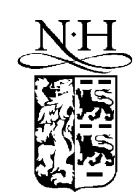

ELSEVIER

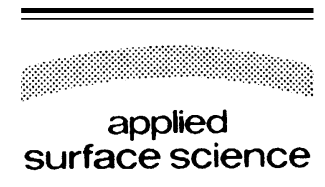

www.elsevier.com/locate/apsusc

\title{
TOF-SIMS characterization of planktonic foraminifera
}

\author{
G. Vering ${ }^{\mathrm{a}}$, C. Crone ${ }^{\mathrm{a}}$, J. Bijma ${ }^{\mathrm{b}}$, H.F. Arlinghaus ${ }^{\mathrm{a}, *}$ \\ ${ }^{a}$ Physikalisches Institut der Universität Münster, Wilhelm-Klemm-Str 10, D-48149 Münster, Germany \\ ${ }^{\mathrm{b}}$ Carbon Group, Alfred Wegener Institute for Polar and Marine Research, D-27570 Bremerhaven, Germany
}

\begin{abstract}
Oceanic sediment properties that are closely related to former environmental (e.g. climatic) parameters are called "proxies". Planktonic foraminifera are small protists which make up part of the plankton. Certain element concentrations, element ratios and isotopic ratios of their calcite shell found in the sediment can be used as proxies reflecting the state of the ocean during the life of the animal; they supply useful information for the reconstruction of environmental parameters. Time-of-flight secondary ion mass spectrometry (TOF-SIMS) was used to examine the inner and outer part of foraminiferal shells, as well as foraminiferal shells dissolved in $\mathrm{HCl}$. High resolution elemental images and mass spectra were obtained from the foraminifera. The data show that TOF-SIMS is a useful technique for determining the elemental distribution and for measuring isotope ratios such as $\delta^{11} \mathrm{~B}$ with high precision in a single foraminiferal shell.
\end{abstract}

(C) 2002 Elsevier Science B.V. All rights reserved.

Keywords: Foraminifera; TOF-SIMS; Mass spectrometry; Isotope ratio; Boron; Proxy

\section{Introduction}

One of the most important scientific challenges today is to understand and quantify the interaction between the atmospheric $\mathrm{CO}_{2}$ budget and the oceanic carbon cycle. The values of at least two components are required to calculate the oceanic carbonate chemistry. This can be any combination of total dissolved inorganic carbon, alkalinity, $\mathrm{pH}$ or related ion concentrations. To estimate variations in the past oceanic carbon cycle, the desired components cannot be observed directly and thus need to be derived from properties that are closely related to the parameter in question. Among others, promising advances were made in the field of boron isotopes in foraminiferal shells as a paleo-pH recorder [1].

\footnotetext{
* Corresponding author. Tel.: +49-251-8339064; fax: +49-251-8339063.

E-mail address: arlinghaus@uni-muenster.de (H.F. Arlinghaus).
}

Foraminifera are unicellular organisms that occur all over the world ocean. They live either in the watercolumn (planktonic species) or on the seafloor (benthic species). During their life cycle, foraminifera precipitate a calcitic shell. Empty shells accumulate in the sediments on the seafloor where they build an important ocean archive. The trace-metal and isotopic composition of foraminiferal shells records seawater chemistry and as such allows the reconstruction of ocean and climate variability on geological timescales [2].

The measurable descriptors for desired but unobservable environmental variables such as temperature, salinity, carbon dioxide concentration and many more are called proxies. Established foraminiferal proxies are, e.g. the stable isotopic compositions $\delta^{11} \mathrm{~B}, \delta^{13} \mathrm{C}$, $\delta^{18} \mathrm{O}$, and trace-metal/Ca ratios like $\mathrm{Sr} / \mathrm{Ca}$ and $\mathrm{Mg} / \mathrm{Ca}$. Further investigation on elemental and isotopic distribution, containing a wide spectrum of elements, e.g. $\mathrm{Ba}, \mathrm{Zn}, \mathrm{Mn}, \mathrm{Co}, \mathrm{Ni}, \mathrm{As}$, or rare earth elements, may 
lead to new proxies. We have investigated the possibility of using time-of-flight secondary ion mass spectrometry (TOF-SIMS) for imaging single foraminiferal shells and determining their elemental and isotopic distribution with high precision.

\section{Experimental}

The SIMS instrument is equipped with a reflectrontype TOF analyzer, an electron impact ion source (primary ion energy $11 \mathrm{keV}$, noble gases) for sputtering, a liquid metal ion gun $\left(25 \mathrm{keV}, \mathrm{Ga}^{+}\right.$, angle of incident to the normal: $45^{\circ}$ ) for imaging, a dual beam ion gun (1-10 keV, noble gases, $\mathrm{O}_{2}{ }^{+}, \mathrm{Cs}^{+}$) for dc presputtering and depth profiling and a low energy electron-gun for charge compensation.

\section{Results and discussion}

\subsection{Lateral elemental distribution}

To determine the lateral differences of elemental concentration ratios, either a whole or a broken shell (provided by the Department of Geology of the University of Bremen) was attached to a silicon substrate via carbon-based conducting adhesives. Fig. 1a depicts the distribution of $\mathrm{Mg}$ (24), $\mathrm{Si}$ (28), and $\mathrm{Ca}$ (40) obtained from an outer part of a foraminiferal shell using a liquid metal ion gun and a scanning area of $500 \mu \mathrm{m} \times 500 \mu \mathrm{m}$. For $\mathrm{Ca}$ and $\mathrm{Mg}$, a homogeneous distribution can be observed. All images show a decrease of intensity from the left to the right part of the shell. This is caused by the primary ion beam coming from the left side, which results in a typical shadow effect due to the round topography. Similar images were also obtained for a variety of other elements such as $\mathrm{Na}, \mathrm{Zn}$, As, and $\mathrm{Sr}$.

Fig. $1 \mathrm{~b}$ shows images of the same elements from the inner part of the shell. The pores are especially visible in the Ca image. From this image, the size of the pores could be determined to be $5-15 \mu \mathrm{m}$ in diameter. The observed Si signal is lower compared to the outer part of the shell. High-concentration Si spots can also be observed on the inner surface.

Fig. 1c shows the distribution of the same elements obtained from a cross-section of a foraminiferal shell wall. The outer surface points towards the right side, the inner surface towards the left side. The Ca image now shows the formerly visible pores as tunnels from the outer to the inner surface of the shell. There is a noticeable difference between the elemental distributions of $\mathrm{Si}$ and $\mathrm{Mg}$. Mg shows a homogeneous distribution over the entire side of the shell, while $\mathrm{Si}$ depicts some high-concentration spots mainly at the outer surface. Additional images with higher magnification could also be obtained; however, for images with very high magnification (field of view smaller than $25 \mu \mathrm{m} \times 25 \mu \mathrm{m}$ ), the lateral resolution decreases due to charging effects.

The images clearly show that the compositional differences between the inner and the outer parts of the foraminiferal shell can readily be detected with TOF-SIMS. Furthermore, the same technique can also be used to directly measure isotopic ratios in the inner or outer parts of the shell. Cleaning the surface with ion sputtering might significantly reduce interferences due to adhering surface contaminants.

\section{2. ${ }^{11} \mathrm{~B} /{ }^{10} \mathrm{~B}$ ratio of foraminiferal shells}

The dominant aqueous species of boron in seawater are $\mathrm{B}(\mathrm{OH})_{3}$ and $\mathrm{B}(\mathrm{OH})_{4}{ }^{-}$. The relative proportions of the two boron species are $\mathrm{pH}$ dependent. The lighter isotope ${ }^{10} \mathrm{~B}$ is enriched in the charged species $\mathrm{B}(\mathrm{OH})_{4}{ }^{-}$. It is also the isotopically lighter $\mathrm{B}(\mathrm{OH})_{4}{ }^{-}$ that is incorporated into carbonate structures. Fluctuations in $\mathrm{pH}$ at the site of calcification can change the abundance of $\mathrm{B}(\mathrm{OH})_{4}{ }^{-}$and thereby the shell's boron isotopic ratio. The boron isotopic ratios measured for foraminiferal shells have to be compared with the ratio of a seawater standard (IAPSO) [3].

Preliminary TOF-SIMS measurements of foraminifera from sediments of the Holocene (GeoB 3603-1) and the Last Glacial Maximum (GeoB 3603-2) and seawater standard (IAPSO) were obtained. For these experiments, single foraminifera were dissolved in $1 \mu \mathrm{l}$ of $2 \mathrm{~N}$ quartz-distilled $\mathrm{HCl}$. The dissolved foraminifera as well as liquid seawater standards were pipetted onto Au-coated Si-wafer surfaces and then dried. First experiments show that the boron isotope ratio changes with increasing analysis time. This was presumably caused by an enrichment of ${ }^{10} \mathrm{~B}$ at the surface of the dried dissolved foraminiferal shell. However, pre-sputtering the surface with a dc $1 \mathrm{keV}$ 


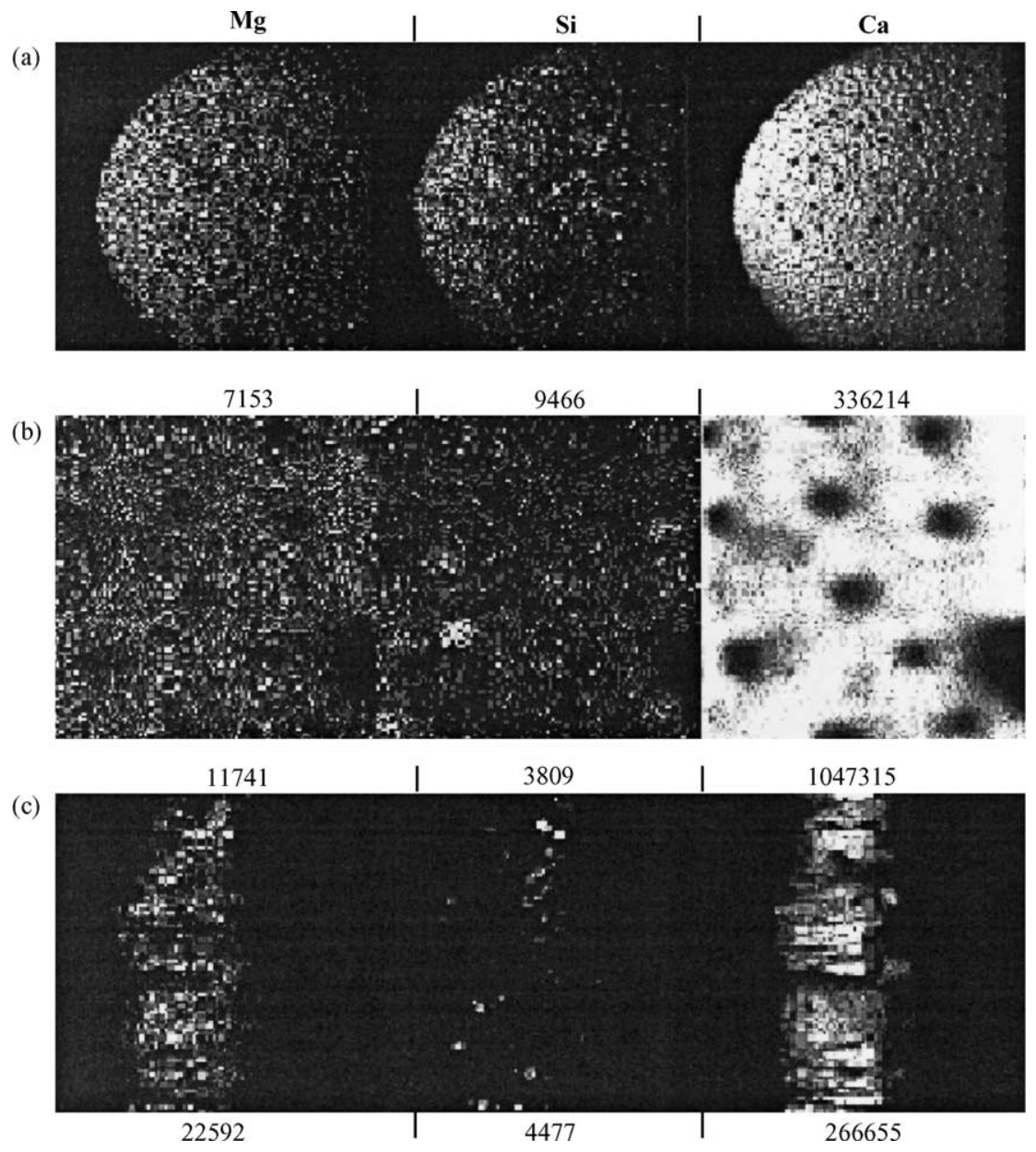

Fig. 1. (a) Outer part of the foraminiferal shell: field of view, $500 \mu \mathrm{m} \times 500 \mu \mathrm{m}$; (b) inner part of the foraminiferal shell: field of view, $50 \mu \mathrm{m} \times 50 \mu \mathrm{m}$; (c) edge of the foraminiferal shell: field of view, $100 \mu \mathrm{m} \times 100 \mu \mathrm{m}$. Number below represents total number of counts of this element during the acquisition.

Xe ion beam (area $500 \mu \mathrm{m} \times 500 \mu \mathrm{m}$; time: $1800 \mathrm{~s}$ (foraminifera), $1230 \mathrm{~s}$ (IAPSO)) almost eliminated this effect.

Fig. 2 shows the boron isotope ratios of the Holocene foraminifera (GeoB 3603-1) and the seawater standard (IAPSO). The 41 (GeoB 3603-1) and 34 (IAPSO) consecutive measurements were carried out with a repetition rate of $5 \mathrm{kHz}$ and a total analysis time of $1800 \mathrm{~s}$ for each spot. The error bars result from the counting statistics (Gaussian form of error propagation). Last Glacial Maximum foraminifera (GeoB 3603-2) as well as the seawater standard (IAPSO) (Fig. 2b) were analyzed under the same conditions (always with pre-sputtering). The data are summarized in Table 1.

The results show that especially for the seawater standard the isotopic boron ratio could be determined with approximately $0.1 \%$ precision. A comparison with the other values shows that the precision of the seawater standard analysis is much higher than that of the foraminiferal results. This can be explained by the differences in obtained yields. The boron yield of the seawater standard is about 100 times higher than the yield of the dissolved foraminifera. A comparison between counting statistics and standard deviation shows that the deviation is limited by the statistical 

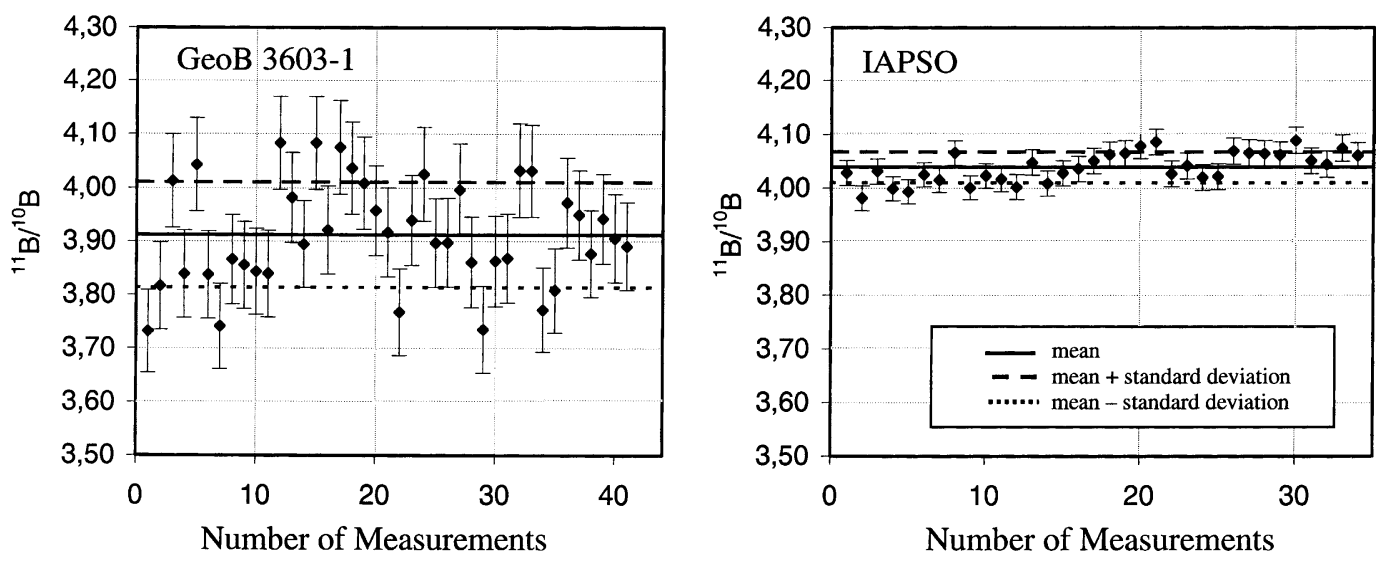

Fig. 2. ${ }^{11} \mathrm{~B} /{ }^{10} \mathrm{~B}$ ratio of Holocene foraminifera (GeoB 3603-1) and seawater standard (IAPSO).

Table 1

${ }^{11} \mathrm{~B} /{ }^{10} \mathrm{~B}$ ratio of Holocene (GeoB 3603-1) and Last Glacial Maximum (GeoB 3603-2) foraminifera and seawater standard (IAPSO)

\begin{tabular}{llllll}
\hline Sample & $\begin{array}{l}\text { Number of consecutive } \\
\text { measurements }\end{array}$ & $\begin{array}{l}\text { Total analysis } \\
\text { time }(\mathrm{min})\end{array}$ & $\begin{array}{l}{ }^{11} \mathrm{~B} /{ }^{10} \mathrm{~B} \\
\text { sample mean }\end{array}$ & $\begin{array}{l}\text { Standard } \\
\text { deviation }\end{array}$ & $\begin{array}{l}\text { Standard error } \\
\text { of the mean }\end{array}$ \\
\hline Fora 3603-1 & 41 & 1230 & 3.913 & 0.099 & 0.015 \\
Fora 3603-2 & 43 & 1290 & 3.815 & 0.094 & 0.014 \\
IAPSO & 34 & 1020 & 4.039 & 0.028 & 0.005 \\
\hline
\end{tabular}

abundance, implying that longer analysis times will improve precision.

A comparison between the measured isotopic ratios and the expected ratios [1] shows that the difference between the measured ratios for Fora 3603-1 and Fora 3603-2 is too high. The deviation is very likely caused by surface contamination. This artifact can be minimized by using elaborate precleaning methods before dissolving the shell. However, the data show promising possibilities of using TOF-SIMS for analyzing single foraminiferal shells. Other techniques such as TIMS (thermal ionization mass spectrometry) currently require approximately 100-200 foraminiferal shells to obtain $0.1 \%$ precision for $\delta^{11} \mathrm{~B}$ ratios.

\section{Conclusion}

The data show that TOF-SIMS is a very useful technique for obtaining information about the variation of oceanic carbonate chemistry. TOF-SIMS can determine variations in distribution, concentration, and concentration ratios for a variety of elements even in single foraminiferal shells. The use of appropriate cleaning methods, better sample preparation techniques and well-characterized standards for calibration would result in higher accuracy. Applying more sensitive and efficient techniques such as resonance postionization [4], which selectively ionizes sputtered neutrals, could improve precision and accuracy in future experiments to a great extent.

\section{References}

[1] A. Sanyal, N.G. Hemming, W.S. Broecker, D.W. Lea, H.J. Spero, G.N. Hanso, Paleoceanography 11 (1996) 513-517.

[2] G. Wefer, W.H. Berger, J. Bijma, G. Fischer, Use of Proxies in Paleoceanography: Examples from the South Atlantic, Springer, Berlin, 1999, pp. 1-68.

[3] N.G. Hemming, R.J. Reeder, G.N. Hanson, Geochim. Cosmochim. Acta 59 (1995) 371-379.

[4] H.F. Arlinghaus, M.T. Spaar, N. Thonnard, A.W. McMahon, T. Tanigaki, H. Shichi, P.H. Holloway, J. Vac. Sci. Technol. A 11 (1993) 2317-2323. 